INTERVENTIONAL CARDIOLOGY AND SURGERY

\title{
Inequalities in coronary revascularisation during the 1990s: evidence from the British regional heart study
}

\author{
R W Morris, P H Whincup, O Papacosta, M Walker, A Thomson
}

Heart 2005;91:635-640. doi: 10.1136/hrt.2004.037507

See end of article for authors' affiliations

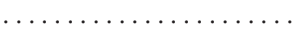

Correspondence to: Dr Richard W Morris, Department of Primary Care and Population Sciences, Royal Free and University College Medical School, London NW3 2PF, UK; r.morris@pcps.ucl. ac.uk

Accepted 14 May 2004
Objective: To investigate the influence of age and social circumstances on probability of revascularisation among British men.

Design: Prospective population based study

Setting: 24 medium sized British towns, none of which contained a hospital undertaking coronary artery bypass surgery.

Subjects: 5814 surviving participants of the BRHS (British regional heart study), aged 52-73 years, with no history of revascularisation when responding to a questionnaire in November 1992.

Main outcomes: Incident coronary revascularisations, as documented in general practitioner records, over the following 7.1 years and coronary angiography investigations reported by men in a further questionnaire in November 1996.

Results: 160 men underwent at least one revascularisation during this period (4.2/1000 person-years). In multifactorial analysis, which included adjustment for incidence of major coronary heart disease or angina, a lower incidence of revascularisation was found among men aged over 65 years in November 1992 (hazard ratio 0.62, 95\% confidence interval (Cl) 0.44 to 0.87 ), among men with manual occupations $(0.73,95 \% \mathrm{Cl} 0.53$ to 1.02$)$, among men living in households possessing no car $(0.44,95 \%$ $\mathrm{Cl} 0.24$ to 0.80$)$ or one car $(0.60,95 \% \mathrm{Cl} 0.42$ to 0.87$)$ compared with two or more cars, among council tenants $(0.49,95 \% \mathrm{Cl} 0.25$ to 0.97$)$, and among men living outside southern England $(0.71,95 \% \mathrm{Cl} 0.51$ to 0.99$)$. Only car ownership was related to the incidence of diagnostic angiography: the odds ratio for angiography for those owning fewer than two cars was 0.62 (95\% $\mathrm{Cl} 0.42$ to 0.89 ).

Conclusion: During the 1990s, there were major inequalities in the probability of undergoing coronary revascularisation between British men according to socioeconomic status, age, and geographic location.
$\mathrm{E}$ arlier studies of provision of tertiary cardiological services in Britain have suggested that coronary revascularisation rates were lower among women, ${ }^{1}$ in socially deprived districts, ${ }^{1-5}$ and among South Asians. ${ }^{36}$ Similar findings have been reported in Canada, ${ }^{7}$ the USA, ${ }^{89}$ Australia, ${ }^{10}$ Italy, ${ }^{11}$ and Finland. ${ }^{12}$ Studies based on routine hospital statistics and aggregated to the level of geographically defined regions are subject to ecological biases and are unable to investigate individual level variables such as smoking status. Moreover, most of these reports are based on data from the early 1990s; recent information is limited.

We have used the British regional heart study (BRHS), ${ }^{13}{ }^{14}$ a prospective study of middle aged British men, to examine the influence of age, a wide range of individual social indicators, cigarette smoking, and geographic location on the likelihood of coronary revascularisation during the period 1992-1999 and taking account of differences in coronary heart disease burden. In a previous report based on coronary revascularisations between 1978 and 1991 current cigarette smoking was a particularly strong determinant of probability of revascularisation, ${ }^{15}$ but social class was not. The analysis reported in this paper focuses on the relation between various measures of social deprivation made at an individual level, geographical location, and age, as well as cigarette smoking, in the 1990s.

\section{METHODS}

The BRHS is a prospective study of cardiovascular disease in 7735 British men aged $40-59$ years at entry in 1978-80. The men were selected from a single general practice in each of 24 medium sized towns. After initial assessment, men have been followed up for all cause mortality and for cardiovascular morbidity through regular two yearly reviews of general practice records. In addition, periodic questionnaires have been completed by men at the start of the study (Q1) and after 5, 13.5, 17.5, and 20 years of follow up. The analyses described here are based on coronary revascularisations carried out from the time of the 13.5 year questionnaire completed in November 1992 (Q92), when men were aged 52-73 years, to the end of 1999. Information on symptoms and social factors at the outset of this period were available principally from Q92 (90\% response rate) supplemented by information collected at other time points.

\section{Coronary revascularisation}

Information on the occurrence and dates of coronary artery bypass grafting and percutaneous coronary angioplasty between November 1992 and 1999 was recorded from regular two yearly reviews of general practice records. Information was cross checked with responses to self completed questionnaires (1992, 1996, 2000). Any discrepancies were resolved with the general practitioner.

\section{Development of major CHD and angina during follow up}

New diagnoses of major CHD or angina were also based on information from the regular two yearly reviews of general practice records. The validity of major CHD events was confirmed by further inquiry. ${ }^{16}$

Abbreviations: $\mathrm{BRHS}$, British regional heart study; $\mathrm{Cl}$, confidence interval; Q1, questionnaire completed at the start of the study; Q92, follow up questionnaire completed in November 1992 


\section{Coronary angiography}

Coronary angiography performed between November 1992 and November 1996 was documented from the self completed questionnaires returned at those time points. In each questionnaire patients were asked whether they had ever had angiography or " $x$ ray" of their coronary arteries.

\section{Social factors}

Information on current smoking status, marital status, housing status, and car ownership was derived from the 1992 questionnaire, as was a social network score, derived by summing the number of positive responses to questions concerning social contacts. ${ }^{17}$ Social class was derived from longest held occupation, coded in accordance with the Registrar General's occupational classification at entry to the study. This comprises seven categories: I (professional), II (managerial), III NM (non-manual/clerical), III M (skilled manual), IV (semiskilled manual), V (unskilled manual), and armed forces. Age at completion of full time education was derived from the 1996 questionnaire.

\section{Area deprivation}

Postcodes for the men's addresses at Q92 were mapped into electoral wards with the help of the 1998 postcode file. The Carstairs, Townsend, and Jarman deprivation scores ${ }^{18}$ according to the 1991 census in the UK were derived for these wards. Because the Carstairs scores were available for the whole of Great Britain (not just England), this deprivation measure was subsequently used. ${ }^{19}$

\section{Statistical methods}

The proportion of men undergoing revascularisation was compared according to the items from Q92 listed above, as well as social class at Q1, region of residence at Q1, and age group when Q92 was administered. Men who underwent a revascularisation procedure before Q92 were excluded from analysis.

Survival to time until revascularisation was analysed with the Cox proportional hazards model as in our previous work. ${ }^{15}$ Data for men who died were regarded as censored observations. The incidence of myocardial infarction or

Table 1 Percentage of men undergoing revascularisation and experiencing angina or $\mathrm{Ml}$ during 7.1 years of follow up from 15 November 1992 to 31 December 1999 according to sociodemographic and medical variables

\begin{tabular}{|c|c|c|c|c|}
\hline Variable & Number & Revascularisation & $\begin{array}{l}\text { Angina/MI } \\
\text { before Q92 }\end{array}$ & $\begin{array}{l}\text { Angina/MI } \\
\text { after Q92 }\end{array}$ \\
\hline \multicolumn{5}{|l|}{ Age group (years) } \\
\hline $50-$ & 414 & $7(1.69 \%)$ & $19(4.59 \%)$ & $34(8.21 \%)$ \\
\hline $55-$ & 1562 & $48(3.07 \%)$ & $108(6.91 \%)$ & $131(8.39 \%)$ \\
\hline $60-$ & 1504 & $50(3.32 \%)$ & 179 (11.9\%) & 123 (8.18\%) \\
\hline $65-$ & 1409 & $37(2.63 \%)$ & $215(15.3 \%)$ & $125(8.87 \%)$ \\
\hline$\geqslant 70$ & 925 & $18(1.95 \%)$ & $166(18.0 \%)$ & $91(9.84 \%)$ \\
\hline \multicolumn{5}{|c|}{ Social class at screening } \\
\hline I & 486 & $16(3.29 \%)$ & $31(6.38 \%)$ & $38(7.82 \%)$ \\
\hline ॥ & 1428 & $47(3.29 \%)$ & $154(10.8 \%)$ & $125(8.75 \%)$ \\
\hline III NM & 566 & $18(3.18 \%)$ & $69(12.2 \%)$ & $51(9.01 \%)$ \\
\hline III $M$ & 2390 & $58(2.43 \%)$ & $306(12.8 \%)$ & $199(8.33 \%)$ \\
\hline IV & 561 & $12(2.14 \%)$ & $71(12.7 \%)$ & $47(8.38 \%)$ \\
\hline V & 208 & $1(0.48 \%)$ & $35(16.8 \%)$ & $24(11.5 \%)$ \\
\hline Armed forces & 164 & $7(4.27 \%)$ & $20(12.2 \%)$ & 19 (11.6\%) \\
\hline \multicolumn{5}{|l|}{ Smoking status } \\
\hline Current & 1140 & $25(2.19 \%)$ & $109(9.56 \%)$ & $106(9.30 \%)$ \\
\hline Never & 1517 & $40(2.64 \%)$ & $121(7.98 \%)$ & $119(7.84 \%)$ \\
\hline Old former & 2068 & $61(2.95 \%)$ & $261(12.6 \%)$ & $186(8.99 \%)$ \\
\hline New former & 1065 & $34(3.19 \%)$ & $194(18.2 \%)$ & $91(8.54 \%)$ \\
\hline Other & 17 & $0(0 \%)$ & $2(11.8 \%)$ & $2(11.8 \%)$ \\
\hline \multicolumn{5}{|c|}{ Housing status at Q92 } \\
\hline Owned & 4733 & $142(3.00 \%)$ & $512(10.8 \%)$ & $417(8.81 \%)$ \\
\hline Privately rented & 178 & $5(2.81 \%)$ & $28(15.7 \%)$ & $17(9.55 \%)$ \\
\hline Council rent & 742 & $10(1.35 \%)$ & $127(17.1 \%)$ & $51(6.87 \%)$ \\
\hline Other & 108 & $2(1.85 \%)$ & $15(13.9 \%)$ & $13(12.0 \%)$ \\
\hline \multicolumn{5}{|l|}{ Car ownership } \\
\hline 0 & 1046 & $17(1.63 \%)$ & $140(13.4 \%)$ & $86(8.22 \%)$ \\
\hline 1 & 3372 & $94(2.81 \%)$ & 437 (13.1\%) & $298(8.91 \%)$ \\
\hline$\geqslant 2$ & 1358 & $49(3.61 \%)$ & $101(7.44 \%)$ & $116(8.54 \%)$ \\
\hline \multicolumn{5}{|c|}{ Carstairs score (quintiles) } \\
\hline 1 & 1116 & $36(3.23 \%)$ & $111(10.0 \%)$ & $90(8.1 \%)$ \\
\hline 2 & 1034 & $30(2.90 \%)$ & $109(10.5 \%)$ & $77(7.5 \%)$ \\
\hline 3 & 1084 & $28(2.58 \%)$ & $130(12.0 \%)$ & $98(9.0 \%)$ \\
\hline 4 & 1074 & $30(2.79 \%)$ & $139(12.9 \%)$ & $101(9.4 \%)$ \\
\hline 5 & 1083 & $25(2.31 \%)$ & $147(13.6 \%)$ & $102(9.4 \%)$ \\
\hline \multicolumn{5}{|l|}{ Social network score } \\
\hline Low $(0-4)$ & 1087 & $30(2.76 \%)$ & $162(14.9 \%)$ & $98(9.0 \%)$ \\
\hline $5-6$ & 1604 & $42(2.62 \%)$ & 177 (11.0\%) & $149(9.3 \%)$ \\
\hline $7-8$ & 1762 & $47(2.67 \%)$ & $206(11.7 \%)$ & $141(8.0 \%)$ \\
\hline High $(9-11)$ & 1335 & $41(3.07 \%)$ & 139 (10.4\%) & $114(8.5 \%)$ \\
\hline \multicolumn{5}{|l|}{ Region of residence } \\
\hline South & 1837 & $58(3.16 \%)$ & 179 (9.74\%) & $150(8.17 \%)$ \\
\hline Midland/Wales & 894 & $23(2.57 \%)$ & $113(12.6 \%)$ & $84(9.40 \%)$ \\
\hline North & 2403 & $61(2.54 \%)$ & $289(12.0 \%)$ & $214(8.91 \%)$ \\
\hline Scotland & 680 & $18(2.65 \%)$ & $106(15.6 \%)$ & $56(8.24 \%)$ \\
\hline
\end{tabular}

MI, myocardial infarction; Q92, follow up questionnaire completed in November 1992

Social classes: I, professional; II, managerial; III NM, non-manual/clerical; III M, skilled manual; IV, semiskilled manual; $\mathrm{V}$, unskilled manual. 
angina during follow up was included as a time dependent covariate. Thus, use of revascularisation according to need measured by coronary disease incidence could be identified.

In addition the incidence of angiography was analysed with regard to the same factors but, as the date of angiography was not known, a logistic regression analysis rather than Cox proportional hazards analysis was used. Recall of CHD at Q92 was included as a confounding factor instead of including occurrence of major events during follow up.

The structure of the sampling involved selection of 24 towns and a sample of men selected from a typical general practice within each town. To take account of this multilevel structure, we repeated the analysis with the statistical package MLwiN (Centre for Multilevel Modelling, Institute of Education, London, UK). Special programs have been written for modelling multilevel survival data in this package, involving the use of a smooth polynomial curve to fit the hazard function. However, as results differed very little with this approach, these are not reported.

\section{RESULTS}

There were 5925 respondents to Q92 (91\% response rate) but 111 had already undergone a revascularisation procedure and were omitted from further analysis, leaving 5814 patients who were followed up from Q92 for 7.1 years. During that period, 125 men underwent their first coronary artery bypass grafting and 42 underwent a first percutaneous coronary angioplasty. Seven men underwent both procedures so in all there were 160 events (4.2/1000 person-years). During the period, 882 men died, including 271 of coronary heart disease, 70 of stroke, and 77 of other cardiovascular disease.

Of the 5814 men, 687 had a non-fatal myocardial infarction or angina according to the medical records before Q92. During the follow up period, a new non-fatal myocardial infarction or angina was recorded for 504 men.

Table 1 shows the numbers and percentages of various subgroups of men undergoing revascularisation and experiencing angina or myocardial infarction before and during the follow up period. For example, prevalence and incidence of angina rose steadily with age group, yet the proportion of revascularisations was lowest in the oldest age group. Similar anomalies occurred for occupational social class, housing status, car ownership, Carstairs deprivation score, social network score, and region of residence.

Figure 1 shows the relations of age to likelihood of revascularisation before and after adjustment for CHD risk and other factors. There was a clear tendency for lower revascularisation incidence among older men, with a particular decline in revascularisation rate above the 60-64 year age group. After adjustment for disease burden, the decline was still greater, occurring from the 55-59 year age group onwards. The association remains after adjustment for social and geographic factors.

Table 2 shows the relations between social factors and likelihood of revascularisation, based on hazard ratios for undergoing revascularisation, firstly adjusted only for age, secondly adjusted also for the incidence of MI or angina during follow up, and thirdly adjusted additionally for other factors listed in table 2 . The second analysis confirmed that men of lower social class, in particular those of social class $\mathrm{V}$ (unskilled manual workers), were very much less likely to undergo revascularisation. Men who owned no car or one car and council tenants were less likely to undergo revascularisation. Men from the south of England appeared more likely than men in other regions to undergo revascularisation. Little relation was seen with smoking status. Men from deprived areas according to the Carstairs index were less likely to undergo revascularisation, and the relation was significant when the Carstairs score was regarded as a continuous variable $(p=0.027)$. Although men with a lower social network score were less likely to undergo revascularisation, this was not significant even when the social network score was regarded as a continuous variable $(\mathrm{p}=0.08)$. Men who reported previous angina, MI, or both were as expected more likely to undergo revascularisation in the follow up period.

The third analysis in table 2, which included all the variables listed in that table, also showed the association of low social class, car ownership, housing status, and region of residence to revascularisation. However, the relations of revascularisation with Carstairs index and social network score were no longer significant $(\mathrm{p}=0.48$ and $\mathrm{p}=0.42$, respectively).

A further analysis was applied to 5712 observations on the remaining significant variables. This showed that men over 65 were only 0.62 (95\% confidence interval (CI) 0.44 to 0.87 )

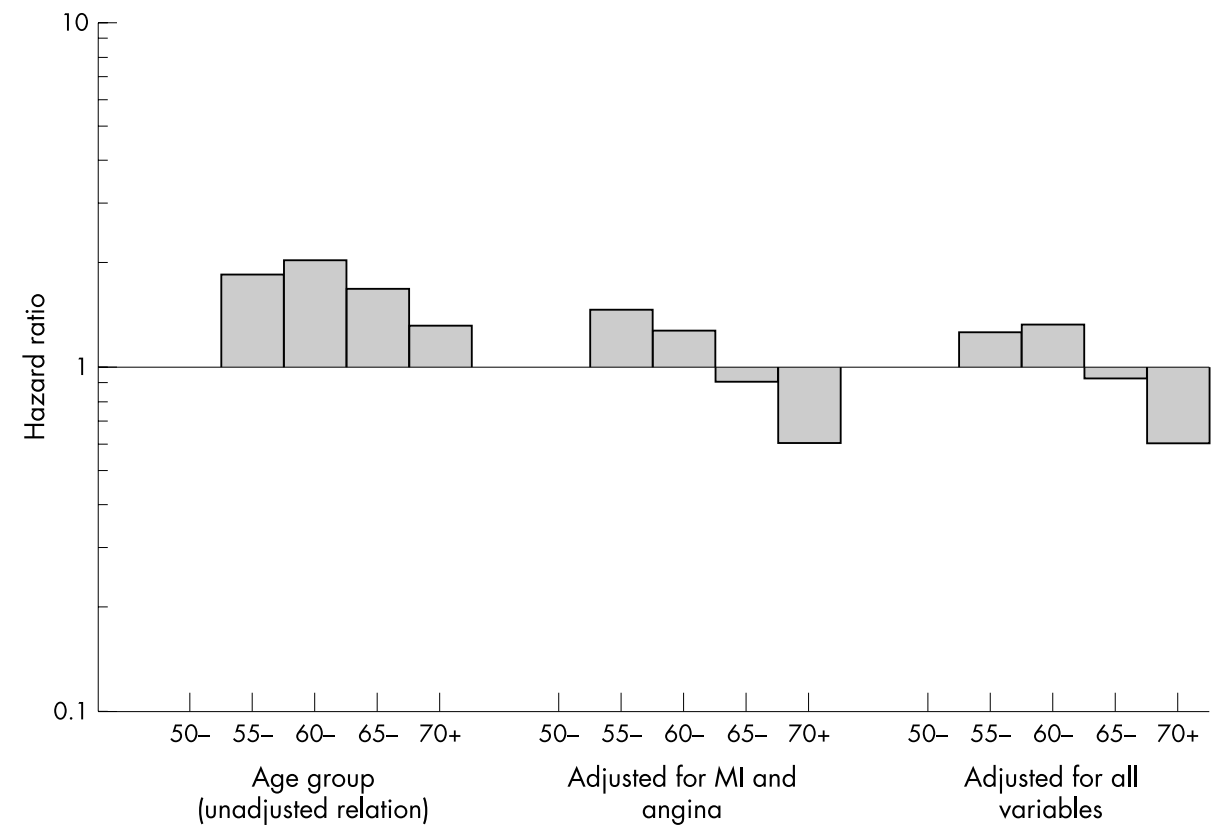

Figure 1 Hazard ratios (log scale) for age groups of men at the follow up questionnaire completed in November 1992 (Q92) unadjusted, adjusted for occurrence of angina or myocardial infarction (Ml), and adjusted also for car ownership, housing status, occupational social class, and region of residence. 
Table 2 Hazard ratios (95\% Cl) for men undergoing revascularisation during 7.1 years of follow up from November 1992 according to sociodemographic and medical variables

\begin{tabular}{|c|c|c|c|}
\hline \multirow[b]{2}{*}{ Variable } & \multicolumn{3}{|l|}{ Adjustments } \\
\hline & Age & Age, $\mathrm{Ml}$, and angina & $\begin{array}{l}\text { Age, Ml, angina, anc } \\
\text { other factors }\end{array}$ \\
\hline \multicolumn{4}{|l|}{ Social class at Q1 } \\
\hline 1 & 1.00 & 1.00 & 1.00 \\
\hline ॥ & $1.00(0.57$ to 1.76$)$ & $0.67(0.38$ to 1.19$)$ & $0.85(0.45$ to 1.61$)$ \\
\hline III NM & $0.97(0.49$ to 1.90$)$ & 0.66 (0.34 to 1.30$)$ & $0.87(0.42$ to 1.84$)$ \\
\hline III $M$ & 0.76 (0.44 to 1.32 ) & $0.46(0.26$ to 0.81$)$ & $0.68(0.35$ to 1.31$)$ \\
\hline IV & $0.67(0.32$ to 1.41$)$ & $0.42(0.2$ to 0.90$)$ & 0.60 (0.25 to 1.44$)$ \\
\hline $\mathrm{v}$ & 0.15 (0.02 to 1.12 ) & $0.06(0.01$ to 0.45$)$ & $0.11(0.01$ to 0.86$)$ \\
\hline \multicolumn{4}{|c|}{ Smoking status at Q92 } \\
\hline Current & 1.00 & 1.00 & 1.00 \\
\hline Never & $1.13(0.68$ to 1.86$)$ & 1.47 (0.89 to 2.43$)$ & $1.27(0.71$ to 2.27$)$ \\
\hline Old former & 1.30 (0.81 to 2.07$)$ & $1.25(0.78$ to 2$)$ & $1.02(0.59$ to 1.75$)$ \\
\hline New former & $1.43(0.85$ to 2.39$)$ & 0.90 (0.53 to 1.52 ) & $0.86(0.48$ to 1.56$)$ \\
\hline \multicolumn{4}{|c|}{ Housing status at $Q 92$} \\
\hline Owned & 1.00 & 1.00 & 1.00 \\
\hline Privately rented & $0.97(0.4$ to 2.36$)$ & $0.77(0.32$ to 1.88$)$ & $0.71(0.22$ to 2.30$)$ \\
\hline Council rent & $0.48(0.25$ to 0.92$)$ & $0.36(0.19$ to 0.68$)$ & $0.47(0.22$ to 1.02$)$ \\
\hline Other & $0.68(0.17$ to 2.74$)$ & $0.53(0.13$ to 2.16$)$ & $1.19(0.29$ to 4.98$)$ \\
\hline \multicolumn{4}{|c|}{ Car ownership at Q92 } \\
\hline$\geqslant 2$ & 1.00 & 1.00 & 1.00 \\
\hline 1 & 0.80 (0.56 to 1.13 ) & $0.55(0.38$ to 0.79$)$ & $0.55(0.37$ to 0.83$)$ \\
\hline 0 & $0.49(0.28$ to 0.86$)$ & 0.30 (0.17 to 0.53$)$ & 0.36 (0.18 to 0.72$)$ \\
\hline \multicolumn{4}{|c|}{ Carstairs deprivation score (1991 census) quintiles } \\
\hline 1 & 1.0 & 1.0 & 1.0 \\
\hline 2 & $0.91(0.56$ to 1.48$)$ & $0.86(0.53$ to 1.39$)$ & $0.88(0.53$ to 1.47$)$ \\
\hline 3 & $0.82(0.50$ to 1.34$)$ & $0.69(0.42$ to 1.14$)$ & $0.97(0.57$ to 1.66$)$ \\
\hline 4 & 0.89 (0.55 to 1.44$)$ & $0.71(0.44$ to 1.16$)$ & $1.22(0.72$ to 2.09$)$ \\
\hline 5 & 0.75 (0.45 to 1.24 ) & 0.60 (0.36 to 1.00$)$ & $1.16(0.65$ to 2.07$)$ \\
\hline \multicolumn{4}{|c|}{ Social network score at Q92 } \\
\hline $0-4$ & 1.00 & 1.00 & 1.0 \\
\hline $5-6$ & $0.91(0.57$ to 1.46$)$ & $1.13(0.71$ to 1.81$)$ & $0.96(0.57$ to 1.63$)$ \\
\hline $7-8$ & $0.91(0.58$ to 1.44$)$ & $1.05(0.66$ to 1.66$)$ & 0.75 (0.44 to 1.28$)$ \\
\hline $9-11$ & $1.05(0.65$ to 1.68$)$ & $1.48(0.92$ to 2.38$)$ & $0.77(0.43$ to 1.37$)$ \\
\hline \multicolumn{4}{|c|}{ Region of residence at Q1 } \\
\hline South & 1.00 & 1.00 & 1.0 \\
\hline Midland/Wales & $0.83(0.52-1.35)$ & $0.62(0.38-1.01)$ & $0.54(0.31$ to 0.93$)$ \\
\hline North & $0.82(0.57-1.17)$ & $0.67(0.47-0.97)$ & $0.59(0.40$ to 0.88$)$ \\
\hline Scotland & $0.86(0.51-1.47)$ & $0.59(0.35-1.00)$ & $0.63(0.34$ to 1.19$)$ \\
\hline
\end{tabular}

times as likely as younger men to undergo revascularisation; men in households with no car and one car were, respectively, 0.44 (95\% CI 0.24 to 0.80 ) and 0.60 (95\% CI 0.42 to 0.87 ) times as likely as those with two cars to undergo revascularisation; men in houses rented from the council were 0.49 (95\% CI 0.25 to 0.97 ) times as likely as owner occupiers to undergo revascularisation; men with a manual occupation were 0.73 (95\% CI 0.53 to 1.02 ) times as likely as those in a non-manual occupation to undergo revascularisation; and men living in the rest of Britain were 0.71 (95\% CI 0.51 to 0.99 ) times as likely as men in the south of England to undergo revascularisation. In a subsidiary analysis of 4578 men, those who completed education before age 16 years were less likely to undergo revascularisation (unadjusted and adjusted hazard ratios 0.55 and 0.71 , respectively).

Table 3 shows the incidence of angiography (self reported) over a four year period from Q92 according to these same factors, in this case dichotomised. Only a doctor's diagnosis of angina or myocardial infarction and car ownership were predictive of angiography after mutual adjustment for all listed factors. Men owning no car or one car had only 0.62 times the odds of undergoing angiographic diagnosis as those owning two cars.

\section{DISCUSSION}

Our analysis has shown that increasing age, lower social status, and residence outside southern England are related to a diminished likelihood of revascularisation, particularly after adjustment for the increased burden of CHD in these groups.
Associations were present for a wide range of social indicators, but the two measures that were most strongly and independently predictive of undergoing revascularisation were car ownership and housing status. Men whose households owned no car or one car were about half as likely to undergo this procedure as those from households with two cars; there was much less difference between men owning one car and men owning no car. Council tenants were less than half as likely as owner occupiers to undergo revascularisation. Few differences were observed in incidence of angiography, except that ownership of two cars was associated with greater usage of this provision also.

The BRHS was able to investigate the question of equitable access to revascularisation services in a population (rather than clinic) based study, with social measures available at an individual rather than area based level. It has been possible to investigate several indices of social deprivation, most measured at the individual level but also including an area deprivation measure. Because exact dates of occurrence of myocardial infarction or angina episodes were available, we were able to adjust for occurrence of disease in a time updated manner throughout the follow up, although clinical and radiological measures of disease severity were unavailable. Our data on revascularisations included both those carried out in the UK National Health Service and those carried out in the private sector, though we were unable to distinguish between them. Lastly, it should be noted that these results refer only to men and that the BRHS men are almost all white. 
Table 3 Percentage of men undergoing coronary angiography between November 1992 and November 1996 according to sociodemographic and medical variables

\begin{tabular}{|c|c|c|c|c|}
\hline Factor & Number & $\begin{array}{l}\text { Number of } \\
\text { angiograms }\end{array}$ & $\begin{array}{l}\text { Unadiusted odds ratio } \\
(95 \% \mathrm{Cl})\end{array}$ & $\begin{array}{l}\text { Adjusted odds ratio } \\
(95 \% \mathrm{CI})\end{array}$ \\
\hline \multicolumn{5}{|l|}{ Age at Q92 (years) } \\
\hline$<65$ & 2840 & $110(3.9 \%)$ & 1.00 & 1.00 \\
\hline$\geqslant 65$ & 1703 & $79(4.6 \%)$ & $1.21(0.90$ to 1.62$)$ & 1.04 (0.74 to 1.46$)$ \\
\hline \multicolumn{5}{|l|}{ Social class } \\
\hline Non-manual & 2056 & $91(4.4 \%)$ & 1.00 & 1.00 \\
\hline Manual & 2365 & $94(4.0 \%)$ & 0.89 (0.67 to 1.20$)$ & 0.89 (0.63 to 1.27$)$ \\
\hline \multicolumn{5}{|l|}{ Car ownership } \\
\hline$\geqslant 2$ & 1151 & $56(4.9 \%)$ & 1.00 & 1.00 \\
\hline $0-1$ & 3341 & $131(3.9 \%)$ & $0.80(0.58$ to 1.10$)$ & 0.62 (0.42 to 0.89$)$ \\
\hline \multicolumn{5}{|l|}{ Housing status } \\
\hline Owned, privately rented, other & 4039 & $165(4.1 \%)$ & 1.00 & 1.00 \\
\hline Council rent & 471 & $23(4.9 \%)$ & 1.21 (0.77 to 1.89$)$ & 1.12 (0.65 to 1.92$)$ \\
\hline \multicolumn{5}{|l|}{ Region of residence } \\
\hline South of England & 1487 & 55 (3.7\%) & 1.00 & 1.00 \\
\hline Rest of Britain & 3056 & $134(4.4 \%)$ & $1.19(0.87$ to 1.65$)$ & $1.02(0.71$ to 1.46$)$ \\
\hline \multicolumn{5}{|l|}{ Deprivation score (Carstairs) } \\
\hline Non-deprived & 2241 & $88(3.9 \%)$ & 1.00 & 1.00 \\
\hline Deprived & 1984 & $85(4.3 \%)$ & $1.10(0.81$ to 1.49$)$ & $1.13(0.79$ to 1.60$)$ \\
\hline \multicolumn{5}{|c|}{ Recall of doctor's diagnosis of coronary heart disease } \\
\hline None & 4137 & 119 (2.9\%) & 1.00 & 1.00 \\
\hline Angina & 183 & $27(14.8 \%)$ & 5.84 (3.74 to 9.14 ) & 5.94 (3.65 to 9.67$)$ \\
\hline MI & 119 & $15(12.6 \%)$ & $4.87(2.75$ to 8.62$)$ & 5.41 (3.02 to 9.71$)$ \\
\hline Both & 89 & $28(31.5 \%)$ & 15.5 (9.56 to 25.1$)$ & $15.9(9.38$ to 26.9$)$ \\
\hline
\end{tabular}

The presence of major age and social differences in likelihood of revascularisation is consistent with earlier reports. $^{1-5}$ The reports do not reflect variations in the effectiveness of revascularisation, which is maintained in older patients, ${ }^{20}$ and would not be expected to vary by social class. Explanation of these differences is likely to be complex; they were present at a time when the provision of revascularisation was increasing, although still at levels insufficient to meet need. ${ }^{21}$ Local differences in accessibility of tertiary cardiac services probably did not exist; none of the study towns had such facilities. However, the higher overall provision of coronary revascularisation in southern England ${ }^{22}$ may well explain the higher revascularisation rates observed in that area of Great Britain. On the basis of our results, which show much stronger age gradients for revascularisation than for angiography, much of the age discrimination probably occurs after initial investigation, as others have reported.$^{23}$ The explanation for the social differences may lie at least partly in access to transport, particularly in the light of the strong gradients relating car ownership to both angiography and revascularisation. This is plausible, since tertiary cardiac services were not locally available. However, the relation with car ownership may also reflect other relevant aspects of material wealth, particularly providing access to private service provision. Moreover, although availability of car transport may be an important factor in its own right, the observation that patients with at least two cars have the highest rates of revascularisation raises the possibility that strong family support (including the availability of a second car driver) may be important. The social differences observed here do not appear to reflect discrimination on the grounds of cigarette smoking habit. Lower likelihood of revascularisation for smokers, noted in an earlier analysis of this study population, ${ }^{15}$ was not observed in the present analysis.

In conclusion, there were strong inequalities in the provision of tertiary cardiological services in the 1990s in Britain, depending on geographic location, material deprivation (car ownership and housing tenure), and age, despite the greater provision compared with the 1980s. The UK Department of Health published a series of National Service
Frameworks, including for coronary heart disease ${ }^{24}$ and for older people, ${ }^{25}$ which placed particular emphasis on the equitable provision of services by age group. Reducing the inequalities suggested by this study should be an important priority for any government and health service.

\section{ACKNOWLEDGEMENTS}

The British regional heart study is funded by the British Heart Foundation and receives additional support from the Department of Health. Opinions expressed in the paper are those of the authors and not necessarily those of the funding bodies.

\section{Authors' affiliations}

R W Morris, O Papacosta, M Walker, A Thomson, Department of Primary Care and Population Sciences, Royal Free and University College Medical School, London, UK

P H Whincup, Department of Community Health Sciences, St George's Hospital Medical School, London, UK

\section{REFERENCES}

1 MacLeod MC, Finlayson AR, Pell JP, et al. Geographic, demographic, and socioeconomic variations in the investigation and management of coronary heart disease in Scotland. Heart 1999;81:252-6.

2 Ben Shlomo Y, Chaturvedi N. Assessing equity in access to health care provision in the UK: does where you live affect your chances of getting a coronary artery bypass graft? J Epidemiol Community Health 1995;49:200-4.

3 Gatrell A, Lancaster G, Chapple A, et al. Variations in use of tertiary cardiac services in part of North-West England. Health Place 2002;8: 147-53.

4 Hippisley-Cox J, Pringle M. Inequalities in access to coronary angiography and revascularisation: the association of deprivation and location of primary care services. Br J Gen Pract 2000;50:449-54.

5 Payne N, Saul C. Variations in use of cardiology services in a health authority: comparison of coronary artery revascularisation rates with prevalence of angina and coronary mortality. BMJ 1997;314:257-61.

6 Feder G, Crook AM, Magee P, et al. Ethnic differences in invasive management of coronary disease: prospective cohort study of patients undergoing angiography. BMJ 2002;324:511-6.

7 Alter DA, Naylor CD, Austin P, et al. Effects of socioeconomic status on access to invasive cardiac procedures and on mortality after acute myocardial infarction. N Engl J Med 1999;341:1359-67.

8 Carlisle DM, Leake BD. Differences in the effect of patients' socioeconomic status on the use of invasive cardiovascular procedures across health insurance categories. Am J Public Health 1998;88:1089-92. 
9 Gregory PM, Malka ES, Kostis JB, et al. Impact of geographic proximity to cardiac revascularization services on service utilization. Med Care 2000;38:45-57.

10 Coory M, Scott IA, Baade P. Differential effect of socioeconomic status on rates of invasive coronary procedures across the public and private sectors in Queensland, Australia. J Epidemiol Community Health 2002;56:233-4.

11 Ancona C, Agabiti N, Forastiere F, et al. Coronary artery bypass graft surgery: socioeconomic inequalities in access and in 30 day mortality. A population-based study in Rome, Italy. J Epidemiol Community Health 2000;54:930-5.

12 Hetemaa T, Keskimaki I, Manderbacka K, et al. How did the recent increase in the supply of coronary operations in Finland affect socioeconomic and gender equity in their use? J Epidemiol Community Health 2003;57:178-85.

13 Shaper AG, Pocock SJ, Walker M, et al. British regional heart study: cardiovascular risk factors in middle-aged men in 24 towns. BMJ (Clin Res Ed) 1981;283:179-86.

14 Walker M, Shaper AG, Lennon L, et al. Twenty year follow-up of a cohort based in general practices in 24 British towns. J Public Health Med 2000;22:479-85.

15 Morris RW, McCallum AK, Walker M, et al. Cigarette smoking in British men and selection for coronary artery bypass surgery. Heart 1996;75:557-62

16 Walker MK, Whincup PH, Shaper AG, et al. Validation of patient recall of doctor-diagnosed heart attack and stroke: a postal questionnaire and record review comparison. Am J Epidemiol 1998;148:355-61.
17 Morgan K, Dallosso H, Ebrahim S. The social engagement score. In: Butler A ed. Ageing: recent advances and creative responses. London: Croom Helm, 1985:298-304

18 Morris R, Carstairs V. Which deprivation? A comparison of selected deprivation indexes. J Public Health Med 1991;13:318-26.

19 Office for National Statistics. 1991 Census: small area statistics and local base statistics. Manchester: ESRC/JISC Census Programme, Census Dissemination Unit, University of Manchester, 2003.

20 TIME Investigators. Trial of invasive versus medical therapy in elderly patients with chronic symptomatic coronary-artery disease (TIME): a randomised trial. Lancet 2001;358:951-7.

21 Martin RM, Hemingway H, Gunnell D, et al. Population need for coronary revascularisation: are national targets for England credible? Heart 2002:88:627-33.

22 Keogh B, Kinsman R. National adult cardiac surgical database report 20002001. London: Society of Cardiothoracic Surgeons of Great Britain and Ireland, 2002.

23 Bowling A, Bond M, McKee D, et al. Equity in access to exercise tolerance testing, coronary angiography, and coronary artery bypass grafting by age, sex and clinical indications. Heart 2001;85:680-6.

24 Department of Health. National service framework for coronary heart disease. London: Department of Health, 2000.

25 Department of Health. National service framework for older people. London: Department of Health, 2001.

\section{IMAGES IN CARDIOLOGY}

\section{Massive thoracic aortic aneurysm}

A 46 year old man presented to his general practitioner with coryzal symptoms. His practitioner incidentally auscultated a precordial murmur and thus referred the patient for transthoracic echocardiography, which showed left ventricular dilatation $(7.4 \mathrm{~cm}$, thin arrow) in association with severe aortic regurgitation and a dilated aortic root $(10 \mathrm{~cm})$. The patient was asymptomatic but recalled that 10 years earlier, a $130 \mathrm{~kg}$ man fell onto his chest while playing cricket and fractured his sternum. He was not marfanoid in appearance. Cardiac magnetic resonance imaging (MRI) showed a $10.4 \mathrm{~cm}$ (anteroposterior and coronal diameter) thoracic aortic aneurysm (thick arrow) involving the aortic

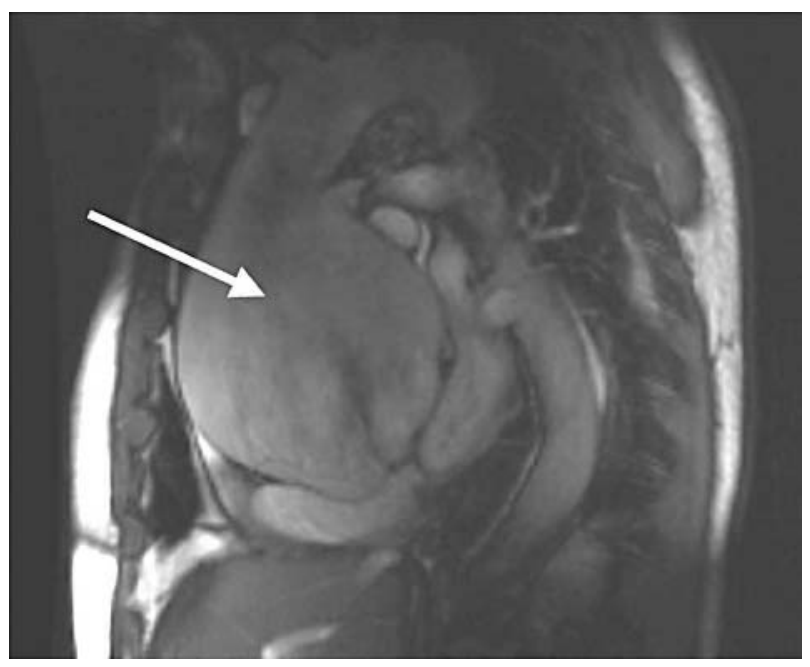

doi: $10.1136 /$ hrt.2004.042697

annulus $(4.2 \mathrm{~cm})$ and ascending aorta, extending up to the origin of the right subclavian artery but not the carotids. The patient underwent aortic valve replacement and aortic root and ascending aorta replacement and currently remains well. Whether the history of major chest trauma is relevant and contributory to his pathology is impossible to say.

K C R Patel

F Leyva

R S Bonser

drkiranpatel@hotmail.com

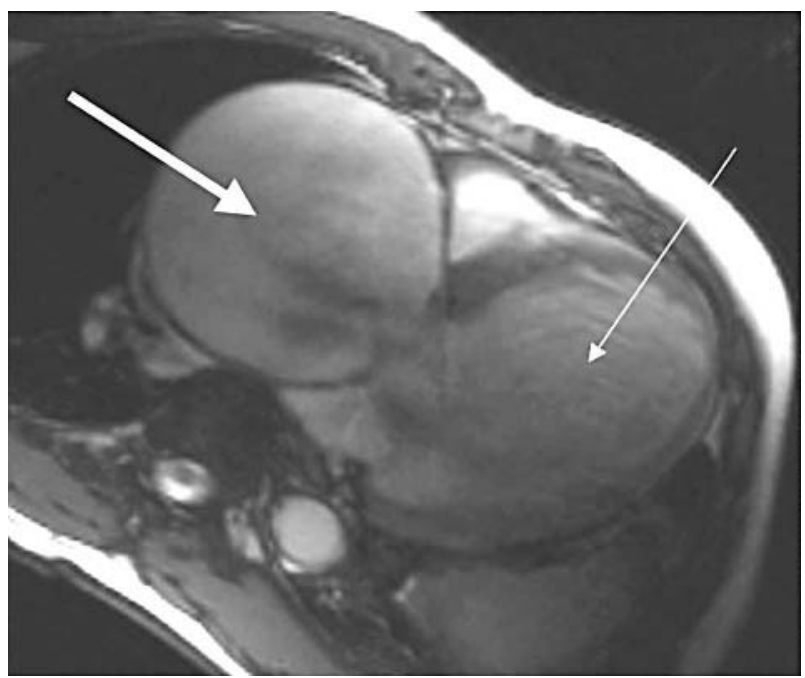

